\title{
BLOKADE QATAR OLEH EMPAT NEGARA SEMENANJUNG ARAB DILIHAT DARI PARADIGMA KONSTRUKTIVIS
}

\author{
Hasya Hanifan \\ Universitas Indonesia \\ e-mail: hasyahanifan@gmail.com
}

\begin{abstract}
ABSTRAK
Tulisan ini akan membahas mengenai kasus blokade negara Qatar oleh empat negara Gulf yakni Arab Saudi, Uni Emirate Arab, Mesir, dan Bahrain. Konflik antara negara Qatar dan negara semenanjung arab lainnya sudah cukup lama terjadi. Hal ini berlanjut pada pemutusan hubungan kerjasama baik dalam hal ekonomi maupun politik, yang di wujudkan dalam aksi blokade. Penulis akan menggunakan paradigma konstruktivis dalam meneliti konflik ini untuk melihat apakah aksi blokade merupakan hasil dari pembentukan identitas dan persepsi yang dibuat oleh Arab yang membuat tindakan Qatar dianggap sebagai tindakan yang akan membahayakan bagi negara mereka, dan juga interpretasi ke empat negara terhadap Qatar. Serta untuk menjelaskan definisi keamanan bagi Arab Saudi sehingga membuat Qatar menjadi ancaman bagi keamanan regional. Argumen utama dari penelitian ini adalah terjadinya blokade Qatar diakibatkan oleh pembentukan identitas negara Qatar oleh empat negara Gulf yang merupakan hasil dari paradigma konstruktivis.
\end{abstract}

Kata Kunci: Qatar, Blokade, GCC, Arab Saudi

\begin{abstract}
This paper will discuss the case of the blockade of Qatar by four Gulf countries, namely Saudi Arabia, the United Arab Emirates, Egypt and Bahrain. The conflict between Qatar and other Arab peninsula countries has been going on for a long time. This continued to the termination of the cooperation relations both in economic and political terms, which was manifested in blockade action. The author will use the constructivist paradigm in examining this conflict to see whether the blockade is the result of the formation of identities and perceptions made by Arabs that make Qatar's actions considered an action that will endanger their country, and also the interpretation of the four countries towards Qatar. As well as to explain the definition of security for Saudi Arabia so as to make Qatar a threat to regional security. The main argument of this research is that the blockade of Qatar is caused by the formation of the identity of Qatar by the four Gulf countries which is the result of the constructivist paradigm.
\end{abstract}

Keywords: Qatar, Blockade, GCC, Qatar 


\section{PENDAHULUAN}

Tulisan ini akan membahas mengenai kasus blokade negara Qatar oleh empat negara Gulf yakni Arab Saudi, Uni Emirate Arab, Mesir, dan Bahrain. Tulisan ini akan menjelaskan mengapa blokade ini terjadi, dengan menggunakan paradigma konstruktivis untuk meneliti kasus ini secara lebih dalam. Konflik antara negara Qatar dan negara semenanjung arab lainnya sudah cukup lama terjadi. Hal ini berlanjut pada pemutusan hubungan kerjasama baik dalam hal ekonomi maupun politik, yang di wujudkan dalam aksi blokade. Penyebab utama dari aksi blokade ini adalah pendanaan Qatar terhadap Muslim Brotherhood (MB). Seperti yang dikatakan oleh Aida Arosoaie (2015), Qatar merupakan satu-satunya negara Gulf yang mendukung penuh Muslim Brotherhood, yang saat itu berada di bawah kepemimpinan pemerintahan Morsi. Namun setelah terjadinya perpecahan dalam Muslim Brotherhood itu, Qatar menolak untuk bekerjasama dengan negara Gulf lainnya. Lalu pada tanggal 7 maret 2014, Arab menyatakan Muslim Brotherhood sebagai kelompok teroris (Arosoaie, 2015). Setelah menyatakan pengumuman tersebut Arab menekan Qatar untuk memberhentikan pendanaan terhadap MB, dan menghentikan siaran Al-Jazeera yang meliput tentang MB di mesir, namun Qatar menolak usulan tersebut. Hal ini lah yang menjadi awal mula terjadinya aksi blokade.

Aksi pertama yang dilakukan oleh Arab beserta dua negara lainnya yakni Bahrain, dan Uni Emirat Arab adalah dengan menarik Duta Besar mereka dari Doha. Arab juga menyatakan akan melakukan tindakan yang lebih ekstrim dengan melakukan penutupan perbatasan dan juga wilayah udara (Arosoaie, 2015). Aksi penarikan Duta Besar ini juga dilakukan karena tiga negara Gulf ini sudah tidak bisa mentolerir dukungan Qatar terhadap MB, yang mereka asumsikan sebagai bentuk campur tangan Qatar dalam urusan internal ketiga negara lainnya. Selain itu terdapat perbedaaan pandangan yang dipengaruhi oleh latar belakang politik, sosial, teologi dan juga kebijakan dari keempat negara tersebut yang membuat adanya perbedaan persepsi terhadap MB ini. Beberapa negara Gulf menganggap MB ini sebagai ancaman terhadap keamanan regional dan kelangsungan negara mereka. Namun beberapa negara lain menganggap MB sebagai sekutu politik yang berguna atau kelompok oposisi yang sah untuk menghadapi ancaman internal maupun eksternal lainnya seperti perluasan pengaruh Iran / Syiah dan munculnya aktor islami Sunni yang lebih ekstrim seperti IS dan Al-Qaeda (Hedges and Cafiero, 2017). 
Tindakan Qatar yang melakukan pendanaan terhadap MB ini bertolak belakang dengan kebijakan ekonomi serta keamanan negara Gulf. Seperti yang di jelaskan oleh Burke dalam reportnya di CSIS menyebutkan beberapa isi kebijakan ekonomi Arab diantaranya adalah mendanai sepenuhnya antiterorisme, mendanai pertahanan yang kuat, dan meningkatkan kontrol atas dugaan pendanaan terorisme. Begitu pula dengan kebijakan keamanan yang dimiliki oleh arab Saudi dan beberapa negara Gulf yang memfokuskan pertahanan mereka terhadap kegiatan antiterorisme yaitu; membuat pasukan keamanan yang berlapis untuk melindungi keamanan internal dan antiterorisme merupakan prioritas utama; fokus pada pengembangan militer untuk ancaman luar dari Iran, Iraq, dan Yemen; dan memfokuskan pertahanan militer pada kekuatan udara dan pertahanan udara berbasis darat (Cordesman and Burke, 2010). Dalam hal ini jelas memerangi terorisme adalah prioritas utama dalam negara Gulf, namun sebaliknya kebijakan luar negeri Qatar justru mendukung pendanaan terhadap kelompok teroris dan menjalankan kerjasama dengan Iran. Hal ini dianggap sebagai intervensi Qatar terhadap kebijakan regional negara Gulf, dan dikhawatirkan akan membahayakan keamanan regional negara-negara Gulf (MEPC, 2017)

Arab Saudi dan Uni Emirat Arab ini mengecam akan meneruskan aksi boikot terhadap Qatar jika Qatar tidak menuruti permintaan mereka. Ke dua Negara arab ini menuntut Qatar untuk memutuskan segala hubungan dan menghentikan bantuan finansial terhadap semua kelompok teroris, menyerahkan tokoh-tokoh teroris yang menjadi buronan Negara arab tersebut, tidak memberikan suaka terhadap teroris buronan Arab Saudi, menghentikan siaran TV Al Jazeera serta menutup kantor berita lainya yang didanai oleh Qatar, mengurangi hubungan diplomasi dalam bentuk apapun dengan Negara Iran, mengurangi diplomasi militer dengan Turki dan meminta Qatar untuk menghentikan pembangunan pangkalan militer Turki di Qatar. Permintaan ini dianggap memberatkan Qatar serta mengurangi kedaulatan dan kebebasan Qatar sebagai sebuah negara. Oleh karena itu Qatar dengan tegas menolak usulan dari negara Gulf tersebut.

Hubungan Qatar dan negara Gulf semakin parah dengan adanya interaksi antara Qatar dan kelompok Hayat Tahrir Al Sham yang berkaitan dengan Al Qaeda, untuk menjamin transfer penduduk di negara itu. Qatar tampaknya telah memperantarai kesepakatan itu dengan berkomunikasi dengan Iran, yang sebagai imbalannya berhasil membebaskan 26 bangsawan 
Qatar yang diculik di Irak dengan imbalan sejumlah pangeran yang harus dibayarkan kepada milisi klien Iran, Kataib Hezbollah (POMEPS, 2017). Hal ini mempertegas posisi Qatar di mata negara Gulf, dimana Qatar jelas memihak Iran dan memilih untuk melanggar persyaratan yang telah diajukan oleh negara Gulf. Melihat bahwa ancaman boikot yang dilakukan dari tahun 2014 tidak membawa pengaruh apapun pada perilaku Qatar, maka Arab Saudi, Uni Emirat Arab, beserta Mesir dan Bahrain melakukan tindakan memblokade seluruh daerah perbatasan Qatar dan memblokade dari jalur darat, udara dan laut. Mesir memblokade alu lintas udara Qatar dengan tidak memperbolehkan Qatar Airways melintas di atas negara tersebut.

Dengan ditutupnya jalur perbatasan dan lalu lintas udara di Qatar tentunya membawa konsekuensi yang buruk bagi pertumbuhan ekonomi dan juga sosial di Qatar. Tujuan dari blokade tersebut adalah untuk membuat Qatar jera, dan kembali bekerjasama dengan negara Gulf dan memutus hubungan dengan Iran. Namun kenyataannya hubungan Qatar dan Iran semakin erat karena Iran memberikan bantuan kepada Qatar untuk memenuhi kebutuhan pangannya akibat dari blokade yang dijalankan negara Gulf.

Hal inilah yang menuntun penulis pada rumusan masalah yang akan dibahas dalam tulisan ini, yaitu mengapa empat negara semenanjung Arab melakukan blokade terhadap Qatar, dilihat dari paradigma Konstruktivis. Penulis akan menggunakan paradigma konstruktivis dalam meneliti konflik ini untuk melihat apakah aksi blokade merupakan hasil dari pembentukan identitas dan persepsi yang dibuat oleh Arab yang membuat tindakan Qatar dianggap sebagai tindakan yang akan membahayakan bagi negara mereka, dan juga interpretasi ke empat negara terhadap Qatar. Serta untuk menjelaskan definisi keamanan bagi Arab Saudi sehingga membuat Qatar menjadi ancaman bagi keamanan regional. Terakhir, untuk melihat apakah pendekatan konstruktivis dapat membantu menyelesaikan konflik internasional yang terjadi pada studi kasus blokade Qatar.

Argumen utama dari penelitian ini adalah terjadinya blokade Qatar diakibatkan oleh pembentukan identitas negara Qatar oleh empat negara Gulf yang merupakan hasil dari paradigma konstruktivis. Penulis akan menggunakan paradigma konstruktivis, karena konstruktivis merupakan pemikiran yang mempercayai bahwa hubungan internasional tidak hanya berkutat pada hal materil seperti ekonomi dan power namun terdapat juga hal lain seperti 
ide, gagasan, budaya, dan juga identitas yang mempengaruhi perilaku sebuah Negara. Sifat sebuah Negara tidak ada atau tercipta begitu saja namun dibangun oleh konstruksi sosial.

Selanjutnya, tulisan ini akan terbagi menjadi 3 bagian yaitu pendahuluan, pembahasan, dan kesimpulan. Poin pertama dari pembahasan tulisan ini akan menjelaskan lebih jauh tentang penyebab utama blokade ini yaitu pendanaan Qatar terhadap Muslim Brotherhood, hubungan kerjasama yang terjalin antara Qatar dan Iran, dan konspirasi media Al-jazeera. Kedua, Tulisan ini akan membahas mengenai teori Konstruktivis yang dibahas oleh Wendt dalam artikelnya yang berjudul “Anarchy, what state's make of it” dan juga artikel dari Raymond Hinnesbuch yang berjudul The Politics of Identity In Middle East International Relation. Poin ketiga akan membahas penerapan dari teori konstruktivis terhadap studi kasus blokade negara Qatar oleh empat negara Gulf. Terakhir merupakan kesimpulan yang akan mencakup seluruh inti dari pembahasan yang telah dibahas pada poin-poin sebelumnya.

\section{PEMBAHASAN}

Aksi pendanaan Muslim Brotherhood (MB) oleh Qatar, yang menurut negara Gulf merupakan salah satu kelompok radikal dan teroris merupakan salah satu alasan terjadinya blokade Qatar. Negara GCC merasa terancam oleh potensi masuknya organisasi rahasia, sikap religius ekstrem, dan aktivisme politik, serta ancaman yang dihasilkan oleh Muslim Brotherhood (Gordon et al, 2017). Terlebih lagi Arab Saudi dan Uni Emirat Arab telah menyatakan kelompok Muslim Brotherhood sebagai kelompok teroris pada tahun 2014, yang selajutnya diikuti oleh Bahrain dan Mesir. Didukung dengan pernyataan dari Dewan Cendekiawan Senior Arab Saudi yang menyatakan bahwa "Kelompok Muslim Brotherhood adalah kelompok teroris dan tidak mewakili metode Islam, melainkan secara membabi buta mengikuti tujuan partisannya yang bertentangan dengan tuntunan agama kita yang anggun, sambil menggunakan agama sebagai topeng untuk menyamarkan tujuannya. Untuk mempraktekkan kebalikannya seperti menghasut, mendatangkan malapetaka, melakukan kekerasan dan terorisme” (AlArabiya English, 2020).

Kerajaan Arab Saudi memandang MB sebagai ancaman terhadap otoritas mereka karena ideologi dan sikap pro-demokrasi yang dianut oleh MB. Perbedaan ideologi islam yang dianut oleh MB menjadi alasan penguatan legitimasi agama untuk mempertahankan kekuatan negara 
Arab Saudi di wilayah kawasan. Ideologi islam yang dianut oleh MB terus beradaptasi dengan perkembangan jaman, berbanding terbalik dengan ideologi islam Wahabi yang dianut oleh Arab Saudi. Wahabi tetap menjadi gerakan konservatif yang didedikasikan untuk penafsiran literal dari Al- Quran, tujuannya adalah untuk mengembalikan islam kepada negara asalnya dan mempersatukan komunitas islam (Lipp, 2019). Untuk itu Arab Saudi semakin khawatir akan adanya penyebaran ideologi dari MB di negaranya, yang bertentangan dengan ideologi Wahabi yang mereka anut Sementara itu Qatar menganggap penting untuk mempererat hubungan dengan MB sebagai strategi kebijakan luar negerinya agar tetap independen dari negara Arab Saudi dan negara lainnya, dan untuk menajdi aktor internasional yang diperhitungkan (Lipp, 2019). Perbedaan pandangan antara Arab Saudi dan Qatar terhadap Muslim Brotherhood membuat adanya kerenggangan antara kedua negara tersebut. Terlebih lagi, Qatar juga menolak untuk tunduk dalam aturan Arab Saudi dan berusaha untuk menjadi negara yang independen tanpa adanya campur tangan Saudi.

Selain itu, hubungan kerjasama yang dijalin oleh Qatar dengan Iran, yang sudah dinobatkan sebagai musuh bersama oleh ke empat negara Gulf tersebut menambah alasan untuk memblokade negara Qatar. Pada kenyataannya, sebelum blokade ini terjadi, hubungan Iran dengan Qatar tidak bisa disebut dekat karena adanya perbedaan persepsi antara kedua negara ini terhadap kelompok Hizbullah dan Kelompok ekstrimis di Suriah. Setelah munculya dugaan keberpihakan Qatar pada Iran yang berujung pada blokade, Iran segera memprioritaskan untuk mengkonfrontasi Arab Saudi dengan mendukung Qatar dalam konflik blokade dari negara GCC yang bertujuan untuk melemahkan kekuatan Arab Saudi dan memperkuat pengaruh Iran di kawasan (Zaccara, 2019).

Sejak awal terjadinya blockade Qatar oleh negara GCC, iran secara terang-terangan memperlihatkan dukungannya terhadap Qatar dan kesediaannya untuk mencegah terjadinya blockade. Iran juga memberikan bantuan makanan kepada Qatar, dan juga membantu agar ekonomi Qatar tetap berjalan setelah blockade terjadi. Blokade yang dilakukan negara GCC ini membuat hubungan antara Qatar dan Iran semakin erat, karena adanya perjanjian dagang antara kedua negara tersebut sebagai ganti dari putusnya hubungan ekonomi antara Qatar dan Arab Saudi dan Uni Emirat Arab (Zaccara, 2019). Kedekatan Qatar dengan Iran membawa kekhawatiran yang besar bagi negara Gulf. Sejarah permusuhan yang panjang antara Arab Saudi 
dan Iran tentunya merupakan faktor besar mengapa Arab Saudi mengecam hubungan antara Iran dan Qatar. Konflik kekuasaan yang terjadi antara Iran dan Arab Saudi menjadi penyebab kekhawatiran itu terjadi. Arab dan UEA khawatir akan semakin meluasnya kekuasaan Iran terhadap kawasan Gulf yang nantinya akan berpengaruh pada berkurangnya dominasi kekuasaan Arab Saudi di kawasan Gulf. Untuk itu Arab berusaha menghentikan hubungan kerjasama dalam bentuk apapun yang terjadi antara Iran dan Qatar.

Penyebab lainnya yaitu konspirasi yang dilakukan oleh media Qatar mengenai pemberitaan negara Gulf juga memperparah konflik yang terjadi antara Qatar dan negara Gulf tersebut. Qatar menggunakan media milik pemerintah yaitu Al Jazeera untuk memperbesar pengaruh MB di timur tengah dan mengkritik para pemimpin di Riyadh, Abu Dhabi, dan Kairo. Pemberitaan yang menyudutkan pemerintah Arab Saudi membuat mereka menarik duta besarnya dari Doha pada tahun 2002, dan pemerintah Arab Saudi bersama Uni Emirat Arab, dan Bahrain akhirnya menarik kembali duta besarnya pada tahun 2014 sebagai respon terhadap pemberitaan Al Jazeera yang berafiliasi dengan MB (Gordon et al, 2017). Qatar juga memanfaatkan media Al Jazeera dalam kebijkan luar negerinya untuk mempromosikan citra yang baik dari negaranya ke seluruh penjuru Timur Tengah (Lipp, 2019).

Dari penjelasan yang telah dijabarkan dalam poin sebelumnya mengenai penyebab terjadinya blokade Qatar oleh negara Gulf, dapat dilihat bahwa blokade Qatar ini terjadi karena adanya ide dan gagasan yang menuntun pada pemberian identitas Qatar sebagi negara pendukung teroris yang mana bertolak belakang dengan kebijakan luar negeri yang dijalankan oleh negara Gulf, sehingga membuat Qatar dikucilkan oleh keempat negara ini. Terlebih lagi dengan latar belakang keempat negara yang merupakan negara Islam Sunni yang memiliki pandangan yang berbeda-beda terhadap kedudukan kelompok teroris muslim dan negara Iran membuat penelitian ini akan dilakukan dengan menggunakan paradigma konstruktivis.

Konstruktivis mempercayai system internasional yang anarki, namun bagi mereka anarki bukanlah sesuatu yang "given" namun terbentuk dari adanya identitas dan kepentingan sebuah Negara yang di konstruk secara sosial. Anarki bukan sesuatu yang "given" atau apa adanya namun anarki terbentuk dari interaksi antar negara. Setiap Negara akan mempunyai reaksi yang berbeda terhadap musuh dan teman, karena mereka beranggapan bahwa musuh itu mengancam namun teman tidak. Wendt beranggapan bahwa anarki ini terbentuk karena relasi 
antara identitas dan kepentingan suatu negara dan negara lainnya. Dengan kata lain, sistem internasional ini terbentuk oleh konstruksi sosial, yang terjadi karena adanya interaksi antar aktor (Wendt, 1992).

Konstruktivisme percaya bahwa tatanan sosial merupakan proses yang tidak ada hentinya dibangun oleh manusia. Konstruktivis berargumen bahwa dalam segala hal yang terjadi dalam tatanan sosial adalah proses yang dibentuk oleh manusia atau terjadi karena adanya konstruksi sosial. Konstruktivis juga melihat aspek penting dalam hubungan internasional tidak hanya dalam hubungan materil seperti keamanan dan ekonomi, namun lebih kepada adanya ide atau gagasan, identitas suatu negara, norma yang berlaku dan juga kebudayaan atau culture yang mempengaruhi world politics. Pada dasarnya konstruktivis percaya pada pandangan strukturalis yang menganggap adanya dominasi struktur dalam sistem internasional. Perbedannya adalah konstruktivis melihat tidak hanya struktur yang dapat mempengaruhi sistem internasional namun terdapat aktor lain yang memiliki makna dan ide yang akan mempengaruhi pandangan dan persepsi terhadap sistem internasional. Oleh karena itu paradgima konstruktivis berpijak pada dua sisi yang akan mempengaruhi interaksi internasional yakni aktor dan struktur. Dimana aktor tersebut mempunyai interpretasi masing-masing dalam memaknai hubungan internasional.

Paradigma konstruktivis lahir sebagai alternatif dari paradigma Realis dan liberalis, karena dua paradigma sebelumnya dianggap kurang mampu menjelaskan perilaku sebuah negara dalam berinteraksi dengan negara lainnya. Untuk itu para pemikir konstruktivis mencoba membuat paradigma baru yang dapat melihat pemaknaan dari perilaku sebuah aktor yang akhirnya akan mempengaruhi interaksinya dengan aktor yang lain, yaitu konstruktivis. Pada awalnya konstruktivis tidak menganggap peran negara sebagai aktor utama layaknya dalam realis dan liberalis. Menurut konstruktivis aktor utama adalah individu yang memiliki kekuatan untuk mempengaruhi atau mengendalikan sebuah makna. Namun akhirnya setelah mendapatkan kritikan dan evaluasi konstruktivis menerima adanya peran negara sebagai aktor maupun unit analisa dengan catatan hal ini terjadi setelah permasalahan yang terjadi dalam negara itu telah selesai. Negara tidak akan pernah mampu menjadi aktor yang baik apabila unsur-unsur didalamnya masih manghadapi berbagai masalah (Faturrahman, 2003). 
Meskipun mendapat banyak kritikan dari pemikir-pemikir realis dan liberalis, yang menganggap konstruktivis memiliki banyak kekurangan dan tidak dapat menyelesaikan suatu masalah atau konflik dalam dunia internasional, namun konstruktivis berhasil menjadi pemikiran dalam hubungan internasional yang meneliti sebuah konflik atau perilaku dengan menelusuri latar belakang historis, dan juga budaya. Seperti dalam kasus blokade Qatar yang cocok untuk diteliti menggunakan paradigma konstruktivis karena adanya latar belakang historis sebagai negara islam yang dapat diteliti untuk mengetahui perilaku negara-negara di Timur Tengah yang akan berbeda dengan negara-negara barat.

Dengan ini konstruktivis mempercayai adanya hubungan yang erat antara ideational atau ide dengan aktor, dan struktur sistem internasional dalam membentuk interaksi internasional. Perilaku aktor tidak hanya dipengaruhi oleh power atau kekuasaan dan perebutan kedaulatan, namun terdapat hal lain seperti ide yang bisa mengubah perilaku negara tersebut dan juga persepsinya terhadap negara lain. Setiap aktor memiliki interpretasi sendiri terhadap aktor lainnya. Identitas suatu aktor dapat dirubah dengan pembentukan identitas yang dibuat oleh aktor lainnya dan juga dapat dilihat dari interaksi yang terjalin dengan aktor lain dalam hubungan internasional. Sebagai contoh pembentukan identitas negara Qatar sebagai pendukung teroris akibat interaksinya dengan kelompok teroris oleh empat negara Gulf membuat Qatar dijauhi. Namun jika Qatar tidak melakukan interaksi dengan kelompok tersebut maka Qatar tidak akan mendapatkan identitas sebagai negara pendukung teroris dan tidak akan terjadi blokade terhadap Qatar oleh ke empat negara tersebut

Selain itu penulis juga akan menggunakan pandangan konstruktivis di Timur Tengah dari artikel Raymond Hinnesbuch (2016), mengatakan bahwa konstruktivis sangat relevan dengan Timur Tengah, mengingat identitas negara semenanjung arab yang erat kaitannya dengan islam dan juga kerajaan membuat pengambilan keputusan dalam kebijakan luar negeri melibatkan identitas dan juga norma yang berlaku di negara tersebut. Terlebih lagi negara Timur Tengah seperti Arab Saudi, Uni Emirat Arab, Mesir dan Qatar selalu dikaitkan pada identitas mereka sebagai negara islam mayoritas Sunni yang membentuk sebuah solidaritas sesama negara mayoritas Sunni (Hinnesbuch, 2016). Kesamaan latar belakang Islam yang dimiliki oleh negara-negara ini semakin mempersulit dalam memahami konflik yang terjadi, karena adanya perbedaan sudut pandang politik sebagai contoh, kasus blokade Qatar. 
Dalam memahami negara Timur Tengah kita tidak bisa hanya melihat satu konteks saja yaitu power atau kekuasaan, namun juga melibatkan ide dan gagasan didalamnya. Dengan latar belakang islam yang kuat yang dimiliki negara-negara tersebut membuat banyak hal perlu diperhitungkan untuk melihat perilaku sebuah negara di Timur Tengah. Power dan juga identitas berjalan beriringan didalamnya. Sistem negara Timur Tengah dan negara dengan model Westphalian berbeda. Jika sistem westphalian adalah tentang kesesuaian identitas dengan kedaulatan, bangsa dan negara, yang memeberikan legitimasi pada negara dan sistem negaranya. Sistem negara Timur Tengah menonjol karena kombinasi kuat dari identitas antara sub-negara dan negara supranasional, bersama, mencairkan dan membatasi kesetiaan masa pada negara yang membedakannya dengan negara lain atau negara tetangganya (Hinnesbuch, 2016).

Sub-negara seperti suku, sekte religius, atau pun kelompok islam yang besar memiliki pengaruh dalam membentuk interaksi antar negara di Timur Tengah. Contohnya seperti interaksi antara Arab Saudi dan Iran yang memburuk dikarenakan perbedaan ideologi dan juga latar belakang islam yang dianut. Yang satu adalah negara islam mayoritas Sunni (Arab) dan yang lainnya adalah negara islam mayoritas Shi'a (Iran). Hal inilah yang membedakan interaksi negara Timur Tengah dengan negara lainnya. Terdapat aktor lain yang sangat diperhitungkan keberadaanya dalam mempengaruhi dominasi kekuasaan dan kedaulatan dan yang menjadi ancaman regional bagi kawasan pesisir Arab, seperti kelompok ekstrimis islam (Al-Qaeda, Hamas, dan ISIS). Hubungan internasional dalam lingkup negara Timur Tengah tidak hanya dapat dliihat dari sisi aktor negara sebgai aktor utama saja, namun banyak kelompok ekstrimis islam yang radikal menjadi aktor penting yang mempengaruhi interaksi antar negara di Timur Tengah. Seperti halnya Al-Qaeda yang menguasai Iran, yang membuat negara lain takut akan kekuasaan dan kekuatan yang terdapat dibalik kelompok tersebut yang akan mengganggu dan mengancam keamanan regional di kawasan Timur Tengah.

Pandangan konstruktivis dalam kasus Qatar dan empat negara Gulf ini terdapat pada interaksi kelima negara dan juga permasalahannya datang pada interaksi Qatar dengan negara penyumbang teroris terbesar di Timur Tengah yakni Iran. Konstruktivis cenderung selalu melihat dari sisi kepentingan negara dan identitasnya. Akar utama dari terjadinya sebuah konflik karena setiap aktor memandang aktor negara lainnya secara negatif dari identitas mereka, dan menempatkan identitas negara mereka sendiri jauh diatas aktor negara lain. Pembentukan 
identitas inilah yang membuat adanya perbedaan persepsi dan juga penamaan identitas terhadap negara lain. Seperti contohnya Iran yang mempunyai identitas sebagai musuh bersama semua negara semenanjung arab, maupun seluruh dunia, dikarenakan banyaknya kelompok teroris yang terbentuk di negara tersebut, membuat negara-negara Arab khawatir akan konsekuensi dan keamanan regional yang dibawa Iran ke wilayah mereka.

Perbedaan persepsi juga terjadi antara Qatar dan negara Gulf lainnya, Qatar yang memandang Muslim Botherhood (MB) sebagai alat politik, namun lain halnya dengan negara Gulf yang menganggap bahwa MB ini merupakan kelompok ekstrimis islam yang dapat membahayakan keamanan dan kedaulatan negara mereka. Beberapa kritik masyarakat terhadap MB mendukung argumen bahwa kelompok ini cenderung menyembunyikan maksud asli dari modus operandinya. Sejak awal hubungan antara Arab Saudi dan MB ini tidak baik. Arab selalu beranggapan bahwa MB merupakan ancaman bagi kekuasaan kerajaan islam tersebut. Untuk itu Arab beserta UEA membujuk serta meyakinkan negara Gulf lainnya untuk bersama memusuhi MB (Hedges and Cafiero, 2017). Arab dan UEA juga berusaha menekan negara anggota GCC untuk menindak lanjuti gerakan tersebut dalam rangka membangun "lingkungan keamanan bebas Muslim Brotherhood" di semenanjung Arab.

Perbedaan persepsi inilah yang memicu terjadinya pembentukan identitas Qatar sebagai negara pendukung terorisme yang berusaha dilakukan oleh Arab Saudi karena keterlibatan Qatar pada pendanaan kelompok teroris dan juga hubungan kerjasama yang dijalani oleh Qatar dan Iran. Arab dan UEA membentuk kampanye melawan Qatar pada tahun 2017, untuk mengajak negara-negara Gulf lainnya agar melawan Qatar. Namun kampanye ini gagal menemukan resolusi untuk menghentikan konflik yang terjadi antara Qatar dan negara Gulf (POMEPS, 2017). Dari hal tersebut dapat dilihat bahwa penyebab pembentukan identitas Qatar sebagai negara pendukung teroris diakibatkan oleh adanya interaksi yang terjalin antara kelompok teroris dan juga Iran dengan Qatar yang membuat Qatar pada akhirnya menjadi musuh bersama keempat negara Gulf tersebut. Dalam konstruktivis hal ini diakibatkan oleh konstruksi sosial yang dibangun oleh negara Arab sehingga membuat negara lain mempunyai pemikiran dan pandangan yang sama terhadap Qatar yang membentuk identitas Qatar sebagai negara yang mendukung tindakan terorisme di kawasan pesisir Arab. 
Dalam pandangan realis, hal ini tidak memungkinkan. Bagaimana Iran dapat menyebabkan terror kepada negara-negara yang jauh lebih besar, seperti yang dilakukan Iran terhadap Amerika. Menurut konstruktivis hal ini dikarenakan konstruksi sosial yang dibangun oleh Iran yang akhirnya membuat negara disekitarnya memandang bahwa Iran adalah negara teroris dan patut untuk dijauhi. Tapi tidak demikian yang dilakukan oleh Qatar, mereka beranggapan bahwa Iran bukanlah Teroris, dan kelompok-kelompok seperti HAMAS, ISIS, dan Al Qaeda bukanlah kelompok teroris namun sebagai kelompok yang memperjuangkan dan memprotes kekuatan Negara besar yang ikut campur di wilayah kekuasaan mereka. Perbedaan pembentukan identitas inilah yang membuat negara Gulf menjalankan aksi boikot mereka terhadap Qatar dengan maksud untuk memutuskan hubungan Qatar dengan Iran. Interaksi negara Qatar, dengan kelompok teroris dan Iran membentuk sebuah identitas Negara Qatar sebagai pendukung terorisme. Qatar yang memutuskan untuk tetap meneruskan hubungnnya dengan Negara tersebut maka terjadilah pemutusan hubungan empat negara Gulf dengan Qatar yang membuat Qatar mengeratkan hubungannya dengan Iran dan juga Turki, dan bergantung pada dua negara tersebut. Pada akhirnya blokade dari keempat negara Gulf tidak membuahkan hasil dan sebaliknya mendorong Qatar untuk semakin mengeratkan hubungannya dengan Iran dan juga Turki disaaat semua negara Gulf tidak memberikan bantuan terhadap Qatar.

\section{KESIMPULAN}

Dari pembahasan yang telah dijabarkan sebelumnya dapat dilihat bahwa alasan utama dari blokade Qatar oleh empat negara Gulf ini adalah untuk menghentikan Qatar melakukan aksi pendanaan kepada kelompok teroris dan juga menghentikan hubungan kerjasama antara Qatar dan Iran. Blokade ini dilakukan untuk mencegah perluasan kekuasaan Iran yang selama ini telah menjadi ancaman terbesar terhadap dominasi kekusaan di kawasan Timur Tengah. Dilatar belakangi juga dengan perbedaan identitas kelompok muslim Sunni dan Shi'a di antara kedua negara tersebut menjadi daftar panjang alasan mengapa kedua negara ini tidak bisa bersatu.

Selain itu pendanaan terhadap MB yang telah dikategorikan sebagai kelompok teroris tentunya membuat empat negara Gulf tidak tinggal diam dan bertindak keras agar Qatar segera menghentikan aksinya tersebut. Tindakan pendanaan ini jelas melanggar kebijakan luar negeri yang telah ditetapkan oleh negara Gulf untuk sama-sama memerangi terorisme dan di kawasan 
pesisir Arab. Untuk itu dalam pandangan konstruktivis konflik ini bermula dari pembentukan identitas terhadap MB dan Iran akibat dari hasil interaksi kedua aktor tersebut yang dapat diketegorikan sebagai terorisme, yang pada akhirnya interksi yang dilakukan Qatar dengan kedua aktor tersbut membuat Qatar menerima atau mendapatkan identitas juga sebagai negara pendukung teroris yang di konstruksi oleh Arab ketika melihat interaksi antar aktor-aktor tersebut. Arab beserta UEA mengajak negara Gulf lainnya untuk melawan Qatar dalam tindakan pendanaannya, karena hal ini lah akhirnya empat negara Gulf Anti-Qatar ini menjalankan blokade terhadap Qatar. dengan kata lain jika Qatar tidak menjalankan atau berinteraksi dengan kelompok teroris dan Iran maka tidak akan ada pembentukan identitas Qatar sebagai negara teroris dan juga tidak akan terjadi blokade yang dijalankan oleh empat negara Gulf tersebut.

\section{DAFTAR PUSTAKA}

Al Arabiya English. 2020. Muslim Brotherhood is a terrorist group: Saudi Arabia's Council of Senior Scholars.

Available https://english.alarabiya.net/en/News/gulf/2020/11/11/Muslim-Brotherhood-is-aterrorist-group-Saudi-Arabia-s-Council-of-Senior-Scholars

Arosoaie, A. (2015) 'Middle East: Saudi Arabia', Counter Terrorist Trends and Analyses, 7(1), pp. 75-78. Available at: https://www.cia.gov/library/publications/the-worldfactbook/geos/sa.html.

Cordesman, A. H. and Burke, A. A. (2010) Saudi National Security and the Saudi-US Strategic Partnership. Available at: https://www.scopus.com/record/display.uri?eid=2-s2.084935094372\&origin=recordpage.

Faturrahman, T. E. (2003) Akar Konflik Internasional dan Penyelesaiannya dalam Persfektif Konstruktivisme, Universitas Indonesia.

Gordon, Phillip. Amos Yadlin and Ari Heistein. 2017. The Qatar Crisis: Causes, Implications, Risks, and the Need for Compromise. The Institute for National Security Studies.

Hedges, M. and Cafiero, G. (2017) 'The GCC and the muslim brotherhood: What does the future hold?', Middle East Policy, pp. 129-153. doi: 10.1111/mepo.12256.

Hinnesbuch, Raymond. (2016) "The Politics of Identity In Middle East International Relation", "International Relation of the Middle East". United Kingdom. Oxfords University Press.

Lipp, Andrew. 2019. The Muslim Brotherhood: Exploring divergent views in Saudi Arabia and Qatar. Iowa State University. 
MEPC (2017) Qatar Censured by GCC Allies | Middle East Policy Council. Available at: https://mepc.org/commentary/qatar-censured-gcc-allies (Accessed: 26 December 2018).

POMEPS (2017) ‘The Qatar Crisis’, (October).

Wendt, Alexander. 1992. "Anarchy Is What States Make of It", International Politics: Enduring Concepts and contemporary issues, $9^{\text {th }}$ Edition. New York. Pearson-Longman, hal 6168

Zaccara, Luciano. 2019. Iran and the Intra-GCC Crisis: Risks and Opportunities. Istituto Affari Internazionali (IAI). 